\title{
HARMONIA VOCÁLICA E EXPRESSÃO ÓTIMA DA VOGAL TEMÁTICA EM VERBOS DO PORTUGUÊS
}

ARCAICO

\author{
Vowel harmony and the optimal expression of the \\ thematic vowel of verbs in archaic Portuguese
}

\author{
Gean Nunes Damulakis*
}

\begin{abstract}
RESUMO
O português desenvolveu, em um grupo específico de verbos, o que tem sido descrito como harmonia vocálica (HV) de altura (HARRIS, 1974; WETZELS, 1995; SCHWINDT, 2007; p. ex.: dormir-durmo; servir - sirvo). Considerando a HV a maneira ótima de expressar a vogal temática (VT) nessas formas, investigamos neste trabalho, sob a perspectiva da Teoria da Otimalidade, a expressão da VT em verbos de terceira conjugação no português arcaico, estágio da língua em que tal harmonia ainda ganhava força. $O$ intuito foi verificar quais eram os padrões de expressão desse morfema no período indicado, investigando as motivações para esses padrões e aquelas que levariam, nos séculos subsequentes, à HV. A partir de coleta de dados em corpus representativo do português arcaico, foram identificados e analisados os seguintes padrões: sérvio (servir); feyro (ferir); e menço (mentir). Defendemos que uma única hierarquia de restrições conseguiria dar conta desses padrões, sendo que, diferentemente do período posterior, a restrição Realize Morfema ainda não dominava IDENT[ \pm alto], e a restrição NoHiatus estava dominada por essas duas.
\end{abstract}

Palavras-chave: Vogal temática, harmonia vocálica, Português arcaico.

* Universidade Federal do Rio de Janeiro. 


\begin{abstract}
It is known that the phenomenon which has been described as vowel height harmony (VH) (HARRIS, 1974; WETZELS, 1995; SCHWINDT., 2007; e. g. dormir - durmo 'to sleep - I sleep'; servir - sirvo 'to serve - I serve') took place in a specific group of verbs in Portuguese. Considering VH the optimal way of expressing the theme vowel (TV) in those forms, we investigated the expression of the TV in verbs of Archaic Portuguese, a period of development of the language in which the $\mathrm{VH}$ was emerging. We intended to see what the patterns of expressing this morpheme were during this period, analyzing the motivations for such patterns and those which would lead to $\mathrm{VH}$ in the following centuries. In a representative corpus of Archaic Portuguese, the following patterns were observed and analyzed: 'sérvio' ('I serve', from servir); 'feyro' ('I hurt' form ferir); and 'menço' ('I lie', from mentir). We claim that a single hierarchy of constraints can account for these patterns, and that the constraint Realize Morpheme did not dominate IDENT [ \pm high], and NoHiatus was dominated by these two constraints in this period.
\end{abstract}

Keywords: Thematic vowel, vowel harmony, Archaic Portuguese.

\title{
1. INTRODUÇÃO ${ }^{1}$
}

O português apresenta, em alguns verbos de segunda e terceira conjugação, o que tem sido descrito como harmonia vocálica (HV) envolvendo altura (HARRIS, 1974; WETZELS, 1995; SCHWINDT, 2007; entre outros). Verbos como beber e sentir, na primeira pessoa do presente do indicativo (assim como em todo o presente do subjuntivo e em algumas formas do imperativo), sofrem alternância vocálica na raiz, o que leva vogais médias a serem realizadas como médias altas, no caso de verbos de $2^{\text {a }}$ conjugação (beber - bebo; [que eu] beba, [que tu] bebas etc.); e altas, no caso dos verbos de $3^{a}$ (sentir - sinto, [que eu] sinta etc.; durmo, [que eu] durma etc.). Esse processo de harmonia é engatilhado pela vogal temática, que, nos verbos de segunda conjugação no português, é média alta /e/ e, nos de terceira, a vogal alta não recuada /i/. A maior parte dos analistas defende que a HV não

1 Este artigo não seria possível sem a contribuição de Marcella Karoline Belo Rodrigues. Agradeço os valiosos comentários de Andrew Nevins, Gisela Collischonn, Alessandro Boechat e Leo Wetzels em versões prévias deste trabalho. Os erros residuais são de minha inteira responsabilidade. 
atinge as vogais médias da raiz de verbos de primeira conjugação, que seria abaixada pela regra de abaixamento, essa de caráter mais geral (elsewhere condition de HARRIS, 1974): (levar - $l[\varepsilon] v o$; [que eu] $l[\varepsilon] v e$; cf. [ele] $b[\varepsilon] b e$, $s[\varepsilon]$ rve etc.).

Nossa pesquisa, entretanto, se debruça sobre um período da história da língua, entre os séculos XIII e XIV, período compreendido no português arcaico (PA), no qual a harmonia vocálica era um fenômeno incipiente, concorrendo com outros padrões em determinados verbos de $3^{\mathrm{a}}$ conjugação $o^{2}$. Encontramos os seguintes padrões predominantes durante esse período: I. feyro (para 'ferir'), II. sérvio (para 'servir') e III. senço (para 'sentir'). Além desses, foram registradas formas alternativas, muito menos frequentes, como aquelas sem expressão da VT (servo, dormo) e alguns casos de HV (sirvo $)^{3}$. Como os casos do I a III são predominantes, como veremos adiante, nossa análise se centra na assunção de que a mesma gramática, diga-se uma mesma hierarquia de restrições, seria capaz de produzir os três padrões distintos, sendo suas diferenças promovidas por questões prosódicas, sobretudo aquelas respeitantes à estrutura silábica e à posição do acento.

Considerando a HV a maneira ótima de expressar a vogal temática (VT) nas formas do português contemporâneo, investigamos neste trabalho a expressão da VT em verbos de terceira conjugação no português arcaico, estágio da língua em que tal harmonia ainda ganhava força, sob a perspectiva da Teoria da Otimalidade, que, entre outras diferenças com modelos teóricos predecessores, opera apenas com restrições, considerando essas universais, mas hierarquizáveis de maneira particular. Houve o intuito de verificar quais eram os padrões de expressão desse morfema no período indicado, investigando as motivações para esses padrões e aquelas que levariam, nos séculos subsequentes, à HV. A partir de coleta de dados em corpus representativo do português arcaico, foram identificados e analisados os seguintes padrões predominantes: sérvio (servir); feyro (ferir); e menço (mentir). Defendemos que uma única hierarquia de restrições conseguiria dar conta desses padrões, sendo que, diferentemente do período posterior, a restrição Realize Morfema ainda não dominava IDENT[ \pm alto], e a restrição NoHiatus estava dominada por essas duas. Sendo assim, mostramos que a HV é resultado da satisfação da restrição que exige a realização fonológica da vogal temática, mesmo que essa realização se dê através da sobrevivência de um único traço distintivo. o trabalho está desenvolvido da seguinte forma: na segunda seção,

2 A harmonia vocálica nos verbos de $2^{\mathrm{a}}$ conjugação não provocaria registro na escrita, posto que continuariam sendo grafados com as médias $<\mathrm{e}>\mathrm{e}<\mathrm{o}>$; por esse motivo, apenas pesquisamos verbos de $3^{a}$.

3 Como veremos adiante, assumimos que uma forma harmonizada (ex. sirvo; durmo) expressa a VT. 
apresentamos os dados coletados em nossa pesquisa. Na terceira, retomamos as análises feitas para a harmonia vocálica nos verbos do português contemporâneo. Na quarta e última seção, estendemos essas análises às alternativas à harmonia, ocorrentes no português arcaico, via restrições.

\section{OS DADOS CONSIDERADOS}

Nossa coleta de dados se centrou em verbos de terceira conjugação que apresentassem vogal média como a última em seu radical, uma vez que esses verbos costumam expressar a harmonia vocálica no português moderno. Foram verbos de terceira conjugação que estivessem na primeira pessoa do singular do presente do indicativo e em formas do presente do subjuntivo. Para controle da qualidade da vogal temática, também foram coletadas, para o mesmo período, as ocorrências dos verbos no infinitivo. As fontes foram as seguintes: 1) Cantigas galego-portuguesas: Cancioneiro da Ajuda, Cancioneiro da Biblioteca Nacional, Cancioneiro da Vaticana, de autoria diversa, datadas entre os séculos XIII a XIV (CANTIGAS MEDIEVAIS GALEGO-PORTUGUESAS, 2016); 2) Cantigas de Santa Maria, do Cancioneiro Mariano, de autoria de Afonso X, oriundas do século XIII (CANTIGAS DE SANTA MARIA, 2016); 3) Testamento de D. Afonso II, da Chancelaria Real de D. Afonso II, datada de 1214 (Prohpor, 2016). Dessa forma, podemos dizer que a pesquisa abrange dados distribuídos entre os séculos XIII e XIV, período inicial do que chamamos de português arcaico (MATOS E SILVA, 2013).

Consultamos também o Testamento de Elvira Sanches, datado de 1193 (FREITAS, 2003) no qual encontramos, para a nossa análise, o item offeyro, que comporá, conforme veremos mais adiante, o padrão de metatéticos. Tanto o Testamento de Elvira Sanches quanto o Auto da Partilha constituem cópias tardias de versões latinas, como demonstrado por estudos de Lindley Cintra e Avelino de Jesus Costa (FREITAS, 2003).

A seguir, encontram-se exemplos das formas flexionadas presentes em nossa coleta. 
1) Formas flexionadas em verbos de $3^{\text {a }}$ conjugação ${ }^{4}$

\begin{tabular}{|ll|}
\hline 1. & servir: sirvo, sérvio, servo, sérvia, sirvamos, serviades, sêrvia. \\
2. & dormir: dórmio, dormo, dormia. \\
3. & sentir: senço, sento, sença, sençades. \\
4. & mentir: menço, mento, mençades. \\
5. & consentir: consento. \\
6. & offerir: offeiro. \\
7. & ferir: feira, feiram. \\
8. & morrer: moiro. \\
\hline
\end{tabular}

A estrutura morfológica considerada das flexões verbais no português é a seguinte: Raiz + Vogal temática + Afixo modo-temporal + Afixo número-pessoal. Sendo assim, na primeira pessoa do presente do indicativo de um verbo como servir, temos: $\operatorname{ser} v+i+\emptyset+o$; no presente do subjuntivo, a primeira pessoa será: serv $+i+a+\emptyset$. A presença, no PA, de flexões como sérvio e sérvia desse verbo, para primeira pessoa do presente do indicativo e do subjuntivo, respectivamente, parece reforçar a ideia de que, ao menos para esse período, essa estrutura, com a presença da vogal temática, poderia ser tomada como a forma subjacente. As formas encontradas podem ser sistematizadas esquematicamente nos seguintes padrões:

\section{2) Padrões de expressão da VT encontrados}

\begin{tabular}{|c|c|}
\hline I. Metatéticos: & $\mathrm{CV} . \mathrm{Ci}+\mathrm{o} \rightarrow \mathrm{CVj} . \mathrm{Co}$ (offeyro; feyra; ${ }^{*}$ sejrvo) \\
\hline II. Fiéis: & CVr.Ci $+o \rightarrow$ CVr.Cio (sérvio, dórmio) \\
\hline III. Coalescentes: & CVN.ti+o $\rightarrow$ CVN.so (menço, senço) \\
\hline IV. Harmonizados: & CVr.Ci+o $\rightarrow$ Ci/ur.Co (sirvo; durmo) \\
\hline V. Apagadores: & $\begin{array}{l}\mathrm{CV}(\mathrm{C}) \cdot \mathrm{C}+\mathrm{i}+\mathrm{o} \rightarrow \mathrm{CV}(\mathrm{C}) \cdot \mathrm{Co} \text { (apagadoras: sento, servo, men- } \\
\text { to, dormo, consento, *fero): menor grupo }\end{array}$ \\
\hline
\end{tabular}

4 Em verbos como menço e senço, a grafia <ç> corresponde a uma sibilante e é proveniente da palatalização da sequência latina tj, que passou por [ts] $>$ [s], "fenômeno que não só se manifestou em formas verbais, como também em palavras de outras classes" (Piel, 1989: 25; apud Colaço \& Cardeira). As ocorrências da primeira pessoa do verbo 'morrer', mesmo sendo de $2^{\text {a }}$ conjugação, foram computadas inicialmente devido ao padrão metatético que apresentavam. É possível imaginar uma forma intermediária *morir (pareando com o espanhol), que não foi, entretanto, capturada em nossa pesquisa. Deixaremos de lado essas ocorrências por conta do registro apenas de 'morrer' no infinitivo. 
Pode-se dizer que a HV apenas ocorreu, com relativamente baixa frequência no período analisado, em verbos cuja sílaba final da raiz era pesada (fechada), não ocorrendo em sílabas leves (abertas; cf. *firo). Em contrapartida, a forma apagadora apenas ocorreu, contrariamente, em verbos cuja sílaba final do radical é leve. É lícito supor que a primeira alternativa para a evitação do hiato foi o apagamento da vogal temática, em verbos que não permitiriam a metátese ou a coalescência. A metátese não seria possível em verbos cuja forma rizotônica houvesse sílaba tônica com coda. Já a coalescência não aconteceria com a junção da vogal temática /i/ com um segmento não coronal, como $/ \mathrm{v} /$ ou $/ \mathrm{m} /$ em $\operatorname{ser} v+i+o$ e $d o r m+i+o$, por exemplo.

A ocorrência mais robusta de formas harmonizadas em verbos cuja vogal do radical era a anterior sugere a probabilidade de que a harmonia tenha se desenvolvido inicialmente pela vogal anterior, atingindo apenas depois a [+ recuada]. Essa hipótese será explorada por nós futuramente.

Neste trabalho, daremos conta dos padrões metatético (feyro; offeyro), fiel (sérvio, dórmio) e coalescente (menço, senço). Por serem os padrões menos frequentes para o período considerado, como veremos a seguir, descartaremos da análise as formas apagadoras (mento, servo, dormo) e as harmonizadas (sinto, durmo).

Nos quadros abaixo, vemos as ocorrências nos dados dos padrões considerados nesta análise, bem como a percentagem de ocorrência do respectivo padrão para cada verbo. Note-se que assumimos que as ocorrências da primeira pessoa do presente do indicativo espelham a realização das formas presente do subjuntivo e vice-versa, contando essas ocorrências para o mesmo padrão. As formas do subjuntivo podem ou não ter realizações da desinência número-pessoal, fato indicado por (+des).

(3) Verbos ferir e offerir ${ }^{5}$ (predominância do padrão metatético)

\begin{tabular}{|l|l|c|c|}
\hline Indicativo & Subjuntivo & Total & $\%$ \\
\hline feyro: 0 & feyra(+des): 3 & 4 & 100 \\
\hline offeyro: 1 & offeyra(+des):0 & & \\
\hline *fero: 0 & *fera(+des): 0 & 0 & 0 \\
\hline *offero: 0 & *offera(+des): 0 & 0 & 0 \\
\hline
\end{tabular}


(4) Verbo dormir (predominância do padrão fiel)

\begin{tabular}{|l|l|c|c|}
\hline Indicativo & Subjuntivo & Total & $\%$ \\
\hline dórmio: 10 & dórmia $(+\mathrm{des}): 3$ & 12 & 92 \\
\hline dormo: 1 & dorma $(+\mathrm{des}): 0$ & 1 & 8 \\
\hline durmo: 0 & durma $(+\mathrm{des}): 0$ & 0 & 0 \\
\hline
\end{tabular}

(5) Verbo servir(predominância do padrão fiel)

\begin{tabular}{|l|l|c|c|}
\hline Indicativo & Subjuntivo & Total & $\%$ \\
\hline sérvio: 6 & sérvia $(+\mathrm{des}): 6$ & 12 & 70,6 \\
\hline servo: 2 & serva $(+\mathrm{des}): 0$ & 2 & 11,8 \\
\hline sirvo: 1 & sirva $(+\mathrm{des}): 2$ & 3 & 17,6 \\
\hline
\end{tabular}

(6) Verbo mentir (predominância do padrão coalescente)

\begin{tabular}{|l|l|c|c|}
\hline Indicativo & Subjuntivo & Total & $\%$ \\
\hline menço: 2 & mença $(+\mathrm{des}): 2$ & 4 & 67 \\
\hline mento: 2 & menta(+des): 0 & 2 & 33 \\
\hline minto: 0 & minta $(+\mathrm{des}): 0$ & 0 & 0 \\
\hline
\end{tabular}

(7) Verbos sentir e consentir (predominância do padrão coalescente)

\begin{tabular}{|l|l|c|c|}
\hline Indicativo & Subjuntivo & Total & $\%$ \\
\hline senço: 3 & sença $(+\mathrm{des}): 6$ & 9 & 69 \\
\cline { 1 - 2 } consenço: 0 & consença(+des): & & 31 \\
\hline sento: 1 & senta $(+\mathrm{des}): 0$ & 4 & 3 \\
\hline
\end{tabular}

\begin{tabular}{|l|l|l|l|}
\hline consento: 3 & consença $(+\mathrm{des}): 0$ & & \\
\hline
\end{tabular}

A ocorrência do padrão com metátese é predominante nos verbos ferir e offerir (quadro (3)); o padrão fiel é predominante nos verbos servir e dormir, como vemos em (4) e (5). Já a coalescência é encontrada nos verbos sentir e mentir (quadros (6) e (7)).

A partir dessa quantificação, podemos verificar que os padrões mais recorrentes são os três primeiros de (2): I. metatético, II. fiel e III. coalescente. o padrão apagador, embora tenha exemplos em vários verbos, tem uma incidência proporcionalmente diminuta. Por sua vez, as formas

6 O item consento apareceu três vezes na mesma cantiga, de autoria de Estêvão da Guarda (1280-1364).

Revista Letras, Curitiba, N. 93 p. 178-192, JAN./JUN. 2016.

ISSN 2236-0999 (VERSÃo ELETRÔNICA) 
harmonizadas, padrão que irá predominar no português a partir do séc. XVI, ainda apresentavam incidência pequena nesse período da história da língua.

Defendemos aqui a possibilidade de dar conta dos padrões I, II e III em uma única gramática (hierarquia de restrições, em uma análise otimalista, como veremos na Seção 4). Desconsiderar os padrões IV e V de (2) nos parece adequado por algumas razões. Em primeiro lugar, a proporção de ocorrência desses padrões, como dissemos, é relativamente pequena nos dados. Em segundo lugar, os padrões fiel, coalescente e metatético são mutuamente excludentes, de maneira que podem ser previstos pela estrutura da sílaba em que figura a forma rizotônica do verbo. Dito de outra maneira, verbos como ferir e offerir (correspondentes ao tipo I, em (2): CV.Ci+o) preferem a forma metatética e repelem a coalescente e a fiel; verbos como servir e dormir (correspondentes ao tipo II, em (2): $\mathrm{CVr} . \mathrm{Ci}+\mathrm{o}$ ) favorecem a forma fiel e rejeitam as formas metatética e coalescente; verbos como mentir e sentir (correspondentes ao tipo III, em (2): CVN.ti+o) preferem a forma coalescente e repelem as formas fiel e metatética. Podemos ver isso no esquema em (8):

(8) Padrões mutuamente excludentes

\begin{tabular}{|l|l|c|c|c|}
\hline Tipo & & Metátese & Fidelidade & Coalescência \\
\hline I. CV.C+ir & ferir/offerir & $\checkmark$ & Não & Não \\
\hline II. CVr.C+ir & servir/dormir & Não & $\checkmark$ & Não \\
\hline III. CVN.t+ir & sentir/mentir & Não & Não & $\checkmark$ \\
\hline
\end{tabular}

Os três padrões apresentados aqui, como majoritários no período arcaico do português, foram perdendo, gradativamente, espaço para a realização de formas harmonizadas da vogal média da raiz no português moderno (COLAÇO; CARDEIRA, 2013). Como o objetivo é dar conta de padrões que representam formas anteriores à harmonização vocálica nesses verbos, abordamos de forma sucinta, na próxima seção, análises da HV no português moderno.

\section{A HARMONIA VOCÁLICA NOS VERBOS DO PORTUGUÊS}

Para enfocar o fenômeno que perseguimos neste trabalho, retomamos, nesta seção, algumas análises sobre a harmonia vocálica nos verbos do português. Três trabalhos são representativos e estão vinculados a propostas teóricas distintas: o trabalho de Harris (1974) nos mostra uma análise sob os princípios da fonologia gerativa linear; no trabalho de Wetzels (1995), o fenômeno é analisado por uma via autossegmental; finalmente, o trabalho de Schwindt (2007) fornece uma análise do fenômeno por restrições. 
O trabalho de Harris (1974) é o primeiro a tratar do fenômeno da HV nos verbos de segunda e de terceira conjugações do português, utilizando o arsenal teórico desenvolvidos em SPE. Harris tributa o fenômeno à atuação de regras ordenadas, sobretudo as de Harmonia e de Abaixamento, e atesta na língua a atuação do Elsewhere Condition (EC). Para Harris, as vogais médias do radical desses verbos sofreriam esses fenômenos, da maneira como esquematizamos abaixo:

(9) Indicativo (1pess.sing), cf. Harris (1974).

\begin{tabular}{|lll|}
\hline & $\mathrm{m}[\mathrm{o}] \mathrm{v}+\mathrm{e}+\mathrm{o}$ & $\mathrm{s}[\mathrm{e}] \mathrm{rv}+\mathrm{i}+\mathrm{o}$ \\
1. Harmonia & $\mathrm{m}[\mathrm{o}] \mathrm{v}+\mathrm{e}+\mathrm{o}$ & $\mathrm{s}[\mathrm{i}] \mathrm{rv}+\mathrm{i}+\mathrm{o}$ \\
2. Truncamento & $\mathrm{m}[\mathrm{o}] \mathrm{v}+\varnothing+\mathrm{o}$ & $\mathrm{s}[\mathrm{i}] \mathrm{rv}+\varnothing+\mathrm{o}$ \\
3. Acento & {$[$ 'mo]v $+\varnothing+\mathrm{o}$} & {$[$ 'si]rv $+\varnothing+\mathrm{o}$} \\
4. Abaixamento & 'bloqueio' (EC) & 'bloqueio' (EC) \\
Saída & {$[$ 'mo]vo } & ['si]rvo \\
\hline
\end{tabular}

Para Harris, é necessário que a regra 4 (Abaixamento) esteja em disjuntividade (situação na qual ambas as regras têm a mesma descrição estrutural em dada derivação) com a regra 1 (Harmonia), para dar conta do abaixamento recorrente na língua para as médias rizotônicas do modo indicativo no PB. O Abaixamento seria bloqueado, entretanto, através de Elsewhwre Condition, sempre que sua descrição estrutural coincidir com a de Harmonia. Vejamos o contexto em que não seria sentida essa disjuntividade: (10) Indicativo (3pess.sing), a partir de Harris (1974).

\begin{tabular}{|c|c|c|c|}
\hline Rep. Subj. & $\mathrm{ap}[\mathrm{e}] \mathrm{l}+\mathrm{a}$ & $\mathrm{m}[\mathrm{\rho}] \mathrm{v}+\mathrm{e}$ & $\mathrm{s}[\mathrm{e}] \mathrm{rv}+\mathrm{e}$ \\
\hline 1. Harmonia & - & - & - \\
\hline 2. Truncamento & - & - & - \\
\hline 3. Acento & $a[p e] l+a$ & {$[\mathrm{~m} \supset] \mathrm{v}+\mathrm{e}$} & {$[$ 'se]rv $+\mathrm{e}$} \\
\hline 4. Abaixamento & $\mathrm{a}[\mathrm{p} p] 1+\mathrm{a}$ & {$[\mathrm{mo}] \mathrm{v}+\mathrm{e}$} & {$\left[{ }^{\prime} \mathrm{s} \varepsilon\right] \mathrm{rv}+\mathrm{e}$} \\
\hline Saída & $\mathrm{a}[$ 'p $\mathrm{p}] \mathrm{la}$ & ['mo]ve & ['se]rve \\
\hline
\end{tabular}

Harris defende que o fenômeno de Harmonia está restrito aos verbos de segunda e de terceira conjugações (ex. mover e servir). Sobre os verbos de primeira conjugação, o autor afirma que as vogais médias do radical estariam sujeitas apenas ao Abaixamento (ex. apelar $>a p[\varepsilon] l o$ ).

O ordenamento final de regras defendido por Harris é uma modificação de um outro prévio fornecido, mas que seria problemático para alguns verbos que podemos chamar de 'mal comportados'. Esses itens, dos quais podemos citar 'fugir' e 'frigir' são verbos de terceira conjugação, mas suas 
vogais radicais altas sofrem abaixamento em formas rizotônicas de segunda e terceira conjugações $(f[0] g e ; f r[\varepsilon] j e)^{7}$. Por conta disso, ele revê sua proposta inicial de ordenamento e considera que existe uma relação de disjuntividade entre as regras de Harmonia e Abaixamento.

Wetzels (1995) se diferencia de abordagens anteriores sobre o tema por trabalhar, em uma análise autossegmental, com a geometria de traços, e por considerar que as distinções entre as alturas vocálicas são dadas por traço de abertura, seguindo Clements (1991), dispensando traços como [alto] e [baixo], por exemplo. O esquema abaixo em (11) representa níveis de abertura contrastivos para vogais. Em um sistema com apenas dois níveis de altura, só haverá necessidade de adotarmos o traço [aberto ${ }_{1}$; se forem três alturas, o aberto $_{2}$ é necessário; nos casos em que o sistema tenha quatro alturas contrastivamente, o traço [aberto ${ }_{3}$ ] entra em ação. Wetzels (1995) assume, portanto, que o PB tem quatro alturas vocálicas distintivamente.

(11) Traços de abertura das vogais do PB. Reproduzido de Wetzels (1995, p. 285)

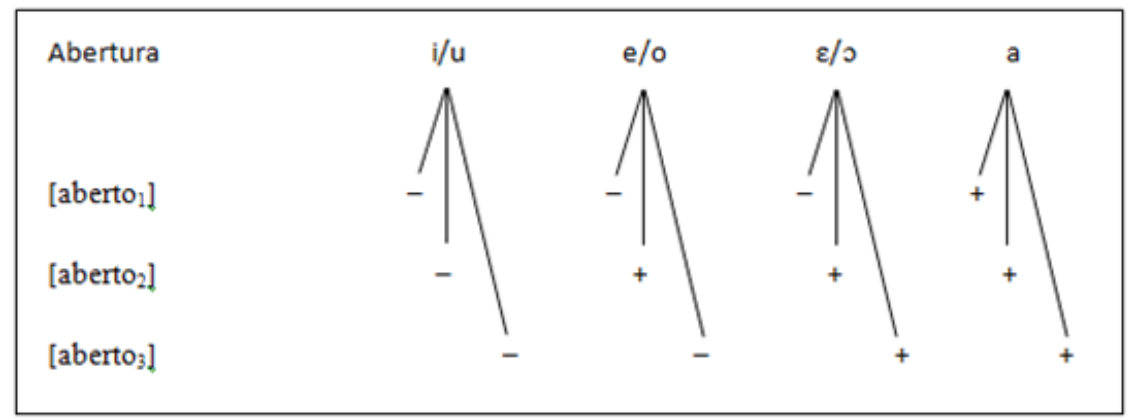

Em Wetzels (1995), a realização da vogal média do radical sofre a influência da vogal temática, através de uma regra de espraiamento de nódulo de abertura dessa vogal, após esta ser apagada para evitar hiato. Para o autor, isso constitui evidência para se considerar que os traços de abertura representem, na geometria de traços, um nódulo de classe independente.

(12) Representação da HV ('Versão redundante’; Cf. WETZELS, 1995, p. 292)

a. Operação: Associe abertura'8

Direção: da direita para a esquerda

Alvo: [-aberto ${ }_{1},+$ aberto $\left._{2}\right]$

Podar ramos: Sim

Domínio: Verbos

7 Harris (1974, p. 74) propõe que verbos como esse possuem um traço +E (Excepcional), o que faria com que esses verbos fossem atingidos por Abaixamento.

8 O diacrítico (abertura') indica, em Wetzels (1995), que o nódulo é flutuante. 
b.

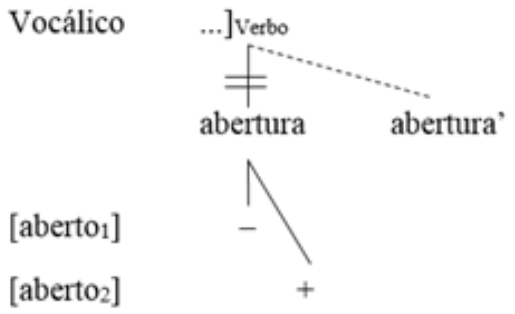

No caso em que o gatilho seja a vogal temática de primeira conjugação /a/, a regra de HV seria bloqueada pelo princípio de Preservação da Estrutura, uma vez que essa regra, na análise de Wetzels, é uma regra lexical $^{9}$. Dessa maneira, o abaixamento nos verbos de primeira conjugação adviria da aplicação da regra de abaixamento. Wetzels também assume a regra de Truncamento antes de HV, considerando ser esta decorrente da reassociação do nódulo de abertura flutuante da vogal apagada. Por fim, Wetzels assume que a HV no PB apenas precisa especificar o alvo ([+aberto3]) - pois ocorreria depois de abaixamento -, sendo todas as demais especificações da regra previsíveis.

O trabalho de Schwindt (2007) analisa os verbos de segunda e terceira conjugações sob a ótica da Teoria da Otimalidade, que prescinde de regras e utiliza apenas restrições universais, que são priorizadas (hierarquizadas) nas línguas de maneira particular. Outro aspecto importante da teoria é o fato de não considerar estágios derivacionais, embora essa característica tenha se enfraquecido em versões mais recentes da teoria.

Segundo Schwindt (2007), as formas de primeira pessoa do presente do indicativo são determinadas pela ação da restrição AGREe, que requer que a vogal da raiz concorde em altura com a vogal temática. Essa restrição domina a de fidelidade IDENT-IO, que milita contra a divergência entre output e input no que se refere ao traço [ \pm alto].

(13) Seleção de sigo (seguir) (SCHWINDT, 2007: p. 10)

9 Na Fonologia Lexical, as regras podem ser lexicais e pós-lexicais, ambos os tipos com características próprias. O Princípio da Preservação de Estrutura, por exemplo, segundo o qual o output de uma regra deve preservar o inventário segmental da língua - não podendo, portanto, gerar alofones - costuma atuar em regras lexicais. No caso em pauta, o inventário vocálico do português não dispõe de outra vogal com a mesma abertura de /a/, o que bloquearia a aplicação da regra nesse caso. 


\begin{tabular}{|l|c|c|}
\hline$/$ seg $+\mathrm{i}+\mathrm{o} /$ & Agree & Ident-IO \\
\hline \hline ségo & $* !$ & \\
\hline ségo & $* !$ & $*$ \\
\hline \multirow{2}{*}{ sígo } & & $*$ \\
\hline
\end{tabular}

Na nossa visão, é problemático considerar Agree uma restrição atuante nesse caso, pois, em sendo essa uma restrição de marcação, ela não pode ter acesso ao input, de maneira que nem $s[$ e]go, nem $s[\varepsilon] g o$ a feririam; um candidato como ['segio], por exemplo, também a feriria, sendo pior que ['sigio], que obedeceria Agree. Além disso, o fato de existir, no PA, a forma 'servio' (mas não *sirvio), por exemplo, parece indicar que o que está em jogo não seria a necessidade de concordância de altura entre a vogal da raiz e a vogal temática, mas a necessidade de expressão fonológica da própria vogal temática.

Sugerimos análise alternativa a essa, que pode ser obtida ao se considerar a harmonia como decorrência da satisfação de duas restrições: uma que exige que algum elemento fonológico do morfema seja realizado (Realize Morfema, R.M., que pode ser satisfeita por um único traço desse morfema; neste caso, o traço de altura) e outra que milita contra o hiato (NoHiatus; Max apenas proíbe o apagamento). Dessa maneira, podemos ver a HV como decorrente da interação uma restrição de caráter morfológico (R.M.) e uma restrição de marcação (NoHiatus). De maneira simplificada, teríamos:

(14) a) Seleção de sigo (seguir)

\begin{tabular}{|l|c|c|c|c|}
\hline$/ \mathrm{seg}+\mathrm{i}+\mathrm{o} /$ & R.M. & NoHiatus & Ident [high]-IO & Max \\
\hline 'sigo & & & $*$ & $*$ \\
\hline 'segio & & $* !$ & & $*$ \\
\hline 'sego & $* !$ & & $*$ & $*$ \\
\hline 'sego & $* !$ & & $*$ & $*$ \\
\hline 'sigio & & $* !$ & $*$ & \\
\hline
\end{tabular}

b) Seleção de sigo (tableau misto) ${ }^{10}$

10 Os tableaux utilizados aqui são do tipo misto: envolvem as marcas de violação (tableau avaliativo) e a comparação entre as restrições (tableau comparativo). As marcações em W indicam que a restrição favorece o vencedor (winner); as marcações de L indicam que a respectiva restrição favorece o perdedor (loser). Pode ser considerado argumento para dominância, por exemplo, 


\begin{tabular}{|l|c|c|c|c|}
\hline$/$ seg+i+o/ & R.M. & NoHiatus & Ident[high]-IO & MAX \\
\hline$*^{\prime}$ 'sigo & & & $*$ & $*$ \\
\hline 'segio & & ${ }^{*} \mathrm{~W}$ & $\mathrm{~L}$ & $\mathrm{~L}$ \\
\hline 'scgo & $* \mathrm{~W}$ & & $*$ & \\
\hline 'sego & $* \mathrm{~W}$ & & $\mathrm{~L}$ & \\
\hline 'sigio & & $* \mathrm{~W}$ & $*$ & $\mathrm{~L}$ \\
\hline
\end{tabular}

O tableau comparativo em $14 \mathrm{~b}$ mostra argumentos para a dominância NoHiatus >> MAX e R.M. >> IDENT[high]-IO. Dito de outra maneira, a harmonia acontece para satisfazer R.M. diante de um quadro de queda da vogal temática para satisfazer a restrição que proíbe hiato. Ou ainda: em uma visão que prescinde passos derivacionais, a HV seria uma necessidade de expressar a VT (através do traço de altura) e evitar o hiato simultaneamente. Ou seja, em um diagrama de Hasse:

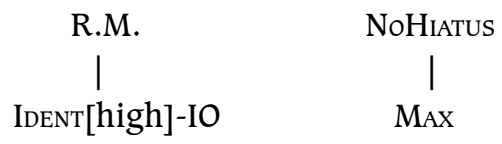

Ainda segundo Schwindt (2007), apenas os verbos de terceira conjugação apresentam a harmonia vocálica de altura, uma vez que nos verbos de segunda conjugação as vogais médias da raiz teriam a mesma especificação de altura que a vogal temática. $O$ autor também considera que exista uma relação paradigmática entre a primeira pessoa do presente do indicativo e as formas do presente do subjuntivo, como vemos em (15).

(15) a) Seleção de sigamos (cf. SCHWINDT, 2007, p. 13):

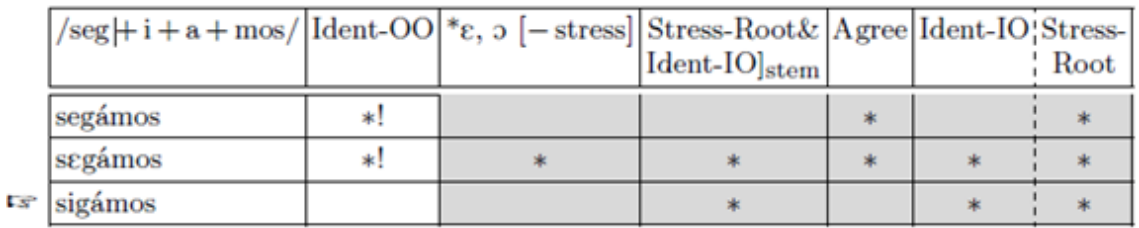

b) Seleção de sigamos

o fato de termo um W acima de (ou à esquerda de) um L (PRINCE, 2002). 


\begin{tabular}{|l|c|c|c|c|}
\hline$/ \mathrm{seg}+\mathrm{i}+\mathrm{a}+\mathrm{mos} /$ & R.M. & NoHiatus & Ident[high]-IO & MAx \\
\hline${ }^{\circ} \mathrm{si}^{\prime}$ gamos & & & $*$ & $*$ \\
\hline se'gamos & ${ }^{*} \mathrm{~W}$ & & $\mathrm{~L}$ & $*$ \\
\hline se'gamos & ${ }^{*} \mathrm{~W}$ & & $*$ & $*$ \\
\hline se'giamos & & ${ }^{*} \mathrm{~W}$ & $\mathrm{~L}$ & $\mathrm{~L}$ \\
\hline si'giamos & & ${ }^{*} \mathrm{~W}$ & $*$ & $\mathrm{~L}$ \\
\hline
\end{tabular}

A restrição mais altamente hierarquizada em (15a) exige que haja correspondência entre a forma do subjuntivo e a da primeira pessoa do presente do indicativo, uma restrição de correspondência output-output. Acreditemos que essa seja uma solução elegante para a correspondência entre as formas do presente do subjuntivo com a primeira pessoa do indicativo no português ${ }^{11}$, por tributar à satisfação à Ident-00 a correspondência entre as formas do presente do subjuntivo e da primeira pessoa do presente do indicativo. Entretanto, há viabilidade de mantermos a mesma hierarquia para dar conta também do subjuntivo, conforme tableau apresentado em $15 \mathrm{~b}$.

\section{A EXPRESSÃo ÓTIMA DA VOGAL TEMÁTICA NOS VERBOS DO PORTUGUÊS ARCAICO}

Nesta seção, analisamos a expressão da vogal temática dos verbos de terceira conjugação. $O$ foco específico nos verbos dessa conjugação se dá devido ao fato de lidarmos com dados escritos, de maneira que não seria tão simples capturar a altura de médias rizotônicas possivelmente harmonizadas em altura com a vogal temática do verbo, devido à coincidência ortográfica entre a média baixa e a média alta. Assim, tanto a grafia de 'l[ $\varepsilon] v o$ ' ('levar') quanto de 'b[e]bo' ('beber') teriam a mesma vogal ortográfica. A harmonização da qual decorre a ocorrência da vogal alta, por outro lado, poderia ser registrada facilmente na escrita. A partir desses achados, podem ser levantadas algumas hipóteses sobre o comportamento das médias, como faremos a seguir. Como dissemos anteriormente, trataremos aqui dos padrões metatético, fiel e coalescente, apresentados na primeira seção, em (2), a partir de uma ótica otimalista.

Defendemos que uma análise por restrições consegue não apenas dar conta do fenômeno em causa, mas também indicar quais são as causas de determinados padrões só ocorrerem com estruturas específicas. Como

11 Para trabalho sobre o 'L-shaped morphome' sugerido por essa relação paradigmática no PB e outras línguas românicas, leia-se Nevins, Rodrigues e Tang (2015). 
ficará claro a seguir, fatores prosódicos relacionados à estrutura silábica e à posição do acento poderão determinar o comportamento da expressão da vogal temática nos verbos de terceira conjugação no PA.

Começaremos nossa análise pelo padrão metatético. Considerem-se as restrições abaixo e observe-se o tableau na sequência.

(16) SWP ${ }^{12}$ : toda sílaba acentuada deve ser pesada.

(17) R.M. (Realize Morfema): para cada morfema no input, algum elemento fonológico deve estar presente no output. (VAN OOSTENDORP, 2005).

(18) NoHiatus: o hiato está proibido.

(19) Contig(uidade): os elementos no output devem estar na mesma disposição de seus respectivos elementos no input.

(20) Seleção de feyro/offeyro (tableau misto)

\begin{tabular}{|l|c|c|c|c|}
\hline$/$ fer $+\mathrm{i}+\mathrm{o} /$ & SWP & R.M. & NoHiatus & ConTiG \\
\hline$*$ a. fejro & & & & $*$ \\
\hline b. fero & ${ }^{*} \mathrm{~W}$ & $* \mathrm{~W}$ & & $\mathrm{~L}$ \\
\hline c. firo & ${ }^{*} \mathrm{~W}$ & & & $\mathrm{~L}$ \\
\hline d. ferio & ${ }^{*} \mathrm{~W}$ & & ${ }^{*} \mathrm{~W}$ & \\
\hline
\end{tabular}

(21) Relações de dominância (feyro/offeyro)

a. SWP $>>$ CONTIG

R.M. $>>$ ConTIG

NoHiatus $>>$ Contig

b.

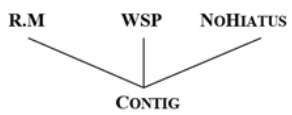

Pelo que vemos em (20) e em (21a, b), podemos deduzir que as três primeiras restrições devem dominar a quarta. Esse fato era de se esperar, uma vez que CONTIG é uma restrição de fidelidade que milita contra a metátese, que efetivamente ocorre nesses casos. $O$ tableau 20 também mostra que a ocorrência de metátese nas formas feyro e offeyro satisfaz, de uma só vez, três restrições (R.M., SWP e NoHiatus). A restrição que milita contra o hiato desfavorece a realização do candidato $d$, que seria o mais fiel. $O$ candidato

12 A restrição é nomeada assim por conta de Stress-to-Weight Principle. 
$b$, apagador, é duplamente ruim, uma vez que esse não tem peso na sílaba tônica, além de ter apagado a vogal temática, violando a restrição R.M. O candidato com harmonia, $c$, apenas é barrado por SWP.

É possível perguntar se o caso em pauta constitui uma metátese e não um fenômeno de outra ordem, como uma pré-vocalização. Não por acaso, controlamos para esse período as ocorrências de infinitivo. Para esse verbo, todas as ocorrências foram de ferir, nunca feirir, por exemplo. Vejamos o seguinte excerto de uma cantiga de escárnio e mal-dizer, de autoria de João Baveca: “(...) feiram per u quer / ca, se vos Deus em armas bem fezer / ferindo em vós, ham eles de caer" (CANTIGAS MEDIEVAIS GALEGO-PORTUGUESAS, 2016).

Vemos que a outra ocorrência do mesmo verbo, no gerúndio, forma arrizotônica, é fer-, não feir-. Isso reforça a assunção de metátese nesses casos, além de atribuir esse fenômeno à necessidade de sílaba pesada sob acento. Também reforça a rechaça à pré-vocalização o fato de haver outros casos com uma composição morfológica semelhante, mesmo com segmentos não coronais, nos quais é atestada a metátese: sabia > saiba.

Para darmos conta das formas fiéis (sérvio, dórmio), devemos levar em consideração o que já vimos das relações de dominância da análise das formas metatéticas. Vimos que o candidato $d$, fiel, em (21) é barrado por duas restrições: aquela que requer peso na sílaba tônica (SWP) e aquela que repele o hiato (NoHiatus). Considerando a estrutura de verbos como dormir e servir, as formas fiéis desses verbos não incorrerão em violação de SWP, uma vez que elas serão silabadas de maneira a respeitar essa restrição: sér.vi.o e dórmi.o. Sendo assim, fica por explicar como podem ser ótimas essas formas, mesmo violando NoHiatus. Vejamos como seria a seleção de candidato ótimo apenas considerando as restrições elencadas anteriormente.

(22) Seleção de sérvio/dórmio (tableau misto; provisório)

\begin{tabular}{|l|c|c|c|c|}
\hline$/$ serv $+\mathrm{i}+\mathrm{o} /$ & SWP & R.M. & NoHiatus & ConTIG \\
\hline a. séjrvo & & & & $*$ \\
\hline b. sérvo & & $* \mathrm{~W}$ & & \\
\hline c. sirvo & & & & \\
\hline d. sérvio & & & $* \mathrm{~W}$ & \\
\hline
\end{tabular}

As restrições envolvidas no tableau (22) não são capazes de dar conta da seleção do output ótimo d, sérvio. O candidato mais harmônico é a forma com HV, por não violar nenhuma das restrições. Sabemos que um candidato como o metatético em $a$ não ocorreria em português, de sorte que é necessária na hierarquia uma restrição que o elimine. Essa restrição é aquela que barra candidatos com sílaba superpesada, estrutura muito mar- 
cada translinguisticamente. O candidato c, forma harmonizada, é barrado por uma restrição que milita contra a disparidade entre input e output no que se refere ao valor do traço [ \pm alto]. A seguir, listamos essas restrições.

(23) Ident [ \pm alto]: segmento no output não deve divergir do respectivo segmento no input em relação ao valor do traço [alto].

(24) * $\mu \mu \mu$ : sílabas superpesadas estão proibidas.

(25) Seleção de sérvio/dórmio (tableau misto; definitivo)

\begin{tabular}{|l|c|c|c|c|c|}
\hline$/$ serv $+\mathrm{i}+\mathrm{o} /$ & IDENT[ \pm alto $]$ & ${ }^{*} \mu \mu \mu$ & R.M. & NoHIATus & ContiG \\
\hline a. sérvio & & & & ${ }^{*}$ & \\
\hline b. séjrvo & & ${ }^{*} \mathrm{~W}$ & & L & $*$ \\
\hline c. sérvo & & & ${ }^{*} \mathrm{~W}$ & L & \\
\hline d. sirvo & ${ }^{*} \mathrm{~W}$ & & & L & \\
\hline
\end{tabular}

o candidato ótimo, o fiel em $a$, viola apenas NoHıatus. Pelo que vemos no tableau (25), a restrição * $\mu \mu \mu$ deve dominar NoHiatus. Em outras palavras, é melhor haver hiato que uma coda com mais de um segmento. Tanto R.M. quanto Ident [ \pm alto] também devem dominar NoHiatus. Isso significa que o hiato é tolerado se for para manter a expressão de morfema - nesse caso, a vogal temática.

(26) Relações de dominância (sérvio/dórmio)

a. $\quad{ }^{*} \mu \mu \mu>>$ NoHiatus

R.M. $>>$ NoHiatus

IDENT[ \pm alto] $>>$ NoHiatus

b.

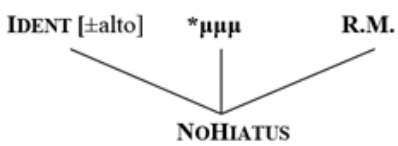

Para dar conta das formas coalescentes, podemos iniciar com as mesmas restrições utilizadas anteriormente devido à semelhança estrutural das formas subjacentes dos verbos "sent $+\mathrm{i}+0$ " e "ment $+\mathrm{i}+0$ " com os "serv $+i+o$ " e "dorm $+i+o$ ". O que chamamos aqui de coalescência é a expressão conjunta de dois segmentos em apenas um, diferente de ambos, mas com algumas propriedades dos que lhe deram origem. Nesse caso, consideramos que todos os traços distintivos de [t] sobrevivem em [s], exceto [+ contínuo], herdado da vogal [i]. Para dar conta desse padrão, assumimos que o PA exclui formas que possuam a sequência [ti] procedente de junção 
morfológica, o que seria proibido pela restrição *t+i, a seguir:

$(27) * t+i$ : está proibida a sequência bimorfêmica [ti ${ }^{13}$.

Ainda no PB a alternância $\mathrm{t} \sim \mathrm{s}$ é verificada quando em junção morfológica com essa vogal (demente $\sim$ demência; referente $\sim$ referência etc.) ${ }^{14}$. Em (27), há outra restrição da família de identidade, desta vez referente ao traço [ \pm contínuo].

(28) Seleção de senço/menço (tableau misto)

\begin{tabular}{|c|c|c|c|c|c|}
\hline$/ \operatorname{sen} t+\mathrm{i}+\mathrm{o} /$ & Ident $[ \pm$ alto $]$ & Ident $[ \pm$ cont $]$ & $* t+i$ & R.M. & NoHiatus \\
\hline \multicolumn{6}{|l|}{ a. sénso } \\
\hline b. sénto & & & & $* \mathrm{~W}$ & \\
\hline c. sínto & *W & & & & \\
\hline d. séntio & & & *W & & $* \mathrm{~W}$ \\
\hline e. sénsio & & & & & $* \mathrm{~W}$ \\
\hline
\end{tabular}

O tableau (29) nos oferece as seguintes informações relevantes sobre dominância:

(29) Relações de dominância (senço/menço)

a. $\quad * t+\mathbf{i}>>$ IDENT $[ \pm$ cont $]$

R.M. > > IDENT [ \pm cont $]$

IDENT [ \pm alto] $>>$ IDENT [ \pm cont]

b.

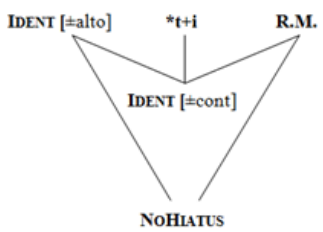

As relações de dominância acima mostram que a expressão fiel de

13 Como bem observa um dos pareceristas, a restrição em pauta é relativamente ad hoc. Salientamos, entretanto, que a alternância t s no português se dá justamente na junção morfológica $/ \mathrm{t}+\mathrm{i} /$, em vários pares lexicais: decente decência, demente demência etc. Embora haja em diversas línguas processos de alternância consonantal similar para esse contexto fonológico, não podemos afirmar neste momento que haja motivação para considerar essa restrição universal, sobretudo por limitar seu escopo à junção morfológica.

14 Em alguns desses casos, a vogal não se encontra presente: doente doença; diferente $\sim$ diferença etc. 
sentio, à semelhança de sérvio, não é permitida devido à atuação da restrição ${ }^{*} t+\mathbf{i}$, que impede a contiguidade desses segmentos de origem bimorfêmica. A satisfação a essa restrição é melhor que incorrer em uma violação decorrente de mudança no valor do traço [contínuo].

\section{CONSIDERAÇõES FINAIS}

Com o intuito de evitar hiato, a metátese [fér $+\mathrm{i}+\mathrm{o} \rightarrow$ féjro] acontece apenas se a posição de coda na sílaba tônica estiver disponível, fazendo com que essa sílaba se torne pesada. É resultado da atuação de duas restrições: aquela que demanda peso na sílaba tônica (SWP) e a que pede a realização de morfema: Realize Morfema (R.M.). Como há metátese, é necessário que a restrição [Contig], que proíbe divergência de disposição dos segmentos no output em relação ao input, esteja dominada. Assim, a expressão da VT se dá através da sua migração para a posição de coda, vazia no input, de sílaba tônica.

Em alguns casos, a sílaba tônica não tem a posição de coda disponível. É o caso dos verbos que produzem os padrões fiel e coalescente. A expressão fiel da vogal temática, como em $[\operatorname{serv}+i+o \rightarrow$ sérvio] e $[$ dorm $+i+o$ $\rightarrow$ dórmio], ocorre por não haver possibilidade de metátese e devido à forte atuação de R.M. O apagamento da vogal temática não ocorre devido ao fato de R.M. dominar NoHiatus. Vale dizer que nas variedades em que a forma apagadora surge (não tratadas aqui - servo; mento etc.), a relação de dominância se inverteria: NoHiatus $>>$ R.M. A forma fiel (sérvio, dórmio) também satisfaz a demanda de peso na sílaba tônica, devido à ocupação da coda pela líquida. Nesse caso, não há possibilidade de realização de apenas traço, o que resultaria em HV, devido a atuação de Ident [ \pm alto].

A coalescência [mént $+\mathrm{i}+\mathrm{o} \rightarrow$ ménso] é a estratégia explorada para impedir o hiato, à custa da identidade do valor do traço [ \pm contínuo]. R.M. é obedecido também nesse caso ([+contínuo]). Aqui a expressão da vogal temática se dará unicamente pelo valor do traço [+contínuo] da VT presente em [s]. Os dados, escassos, não deixam a certeza de que esse seja, de fato, o ponto crucial. Existe a possibilidade de essa estratégia ser independente da necessidade de manter um traço do morfema (nesse caso, assumindo o [ \pm contínuo]), sendo /ti $/ \rightarrow[\mathrm{s}]$ uma demanda de outra ordem. De todo modo, podemos dizer que essa forma não viola NoHiatus, como o faz as formas fiéis dórmio e sérvio.

A análise otimalista explica a mudança através da rerranqueamento de restrições. Sendo assim, em estando corretas essas hierarquias, a harmonia no português moderno apenas passaria a ocorrer depois de R.M. 
e NoHiatus serem promovidas, no ranqueamento, acima de Ident $[ \pm \text { alto }]^{15}$. Consideramos que a satisfação de R.M. pode ser alcançada a partir da realização de qualquer traço dos segmentos do morfema. Uma vez tendo o morfema apenas um segmento, qualquer valor de traço desse segmento, não compartilhado por segmentos adjacentes, satisfaz essa restrição, que deve dominar as restrições de identidade referentes ao traço remanescente. No caso em pauta, os traços serão os [alto] e [contínuo]. Vejamos a hierarquia única que dá conta dos três padrões:

\begin{tabular}{|c|c|c|c|c|c|c|}
\hline$/ \operatorname{sen} t+\mathrm{i}+\mathrm{o} /$ & Ident [ \pm alto] & $* t+i$ & R.M. & SWP & Ident $[ \pm$ cont $]$ & NoHiatus \\
\hline a. sento & & & $* !$ & & & \\
\hline b. sinto & $* !$ & & & & & \\
\hline c. séntio & & $* !$ & & & & * \\
\hline$\leftrightarrow \mathrm{d}$. senso & & & & & * & \\
\hline
\end{tabular}

\begin{tabular}{|l|c|c|c|c|c|c|}
\hline$/$ dorm $+\mathrm{i}+\mathrm{o} /$ & Ident [ \pm alto] & $* \mathrm{t}+\mathbf{i}$ & R.M. & SWP & Ident [ \pm cont] & NoHiatus \\
\hline a. dormo & & & $* !$ & & & \\
\hline b. durmo & $* !$ & & & & & \\
\hline c. dórmio & & & & & $*$ \\
\hline
\end{tabular}

\begin{tabular}{|c|c|c|c|c|c|c|}
\hline$/$ fer $+\mathrm{i}+\mathrm{o} /$ & Ident [ \pm alto] & $* t+i$ & R.M. & SWP & Ident $[ \pm$ cont $]$ & NoHiatus \\
\hline a. fero & & & $* !$ & $*$ & & \\
\hline b. firo & $* !$ & & & * & & \\
\hline c. fejro & & & & & & * \\
\hline
\end{tabular}

No português moderno, a expressão da vogal temática se dá através da permanência de um de seus traços (altura) na raiz, obedecendo a Realize Morfema (R.M.). Ao satisfazer essa restrição dessa maneira, a forma pode prescindir da VT em sua posição de origem, satisfazendo, simultaneamente, a restrição NoHiatus. É essa restrição que impede a realização da vogal temática antecedendo outra vogal. Sendo assim, podemos dizer que a passagem do PA ao PM implicou o seguinte rerranqueamento:

15 Vale ressaltar que a OT ainda carece de dispositivos metodológicos que expliquem satisfatoriamente promoções e demoções de restrições no decorrer do tempo. Há algumas análises que reinterpretam a conspiração, que se daria no sentido de promoção de determinada(s) restrição(ões) na história da língua. No nosso caso, isso se poderia se refletir numa espécie de conspiração para promover padrões silábicos menos marcados (HORA; LUCENA, 2008; RODRIGUES, 2007, entre outros), consubstanciada na promoção de NoHiatus. Essa questão, entretanto, foge ao escopo deste trabalho. 

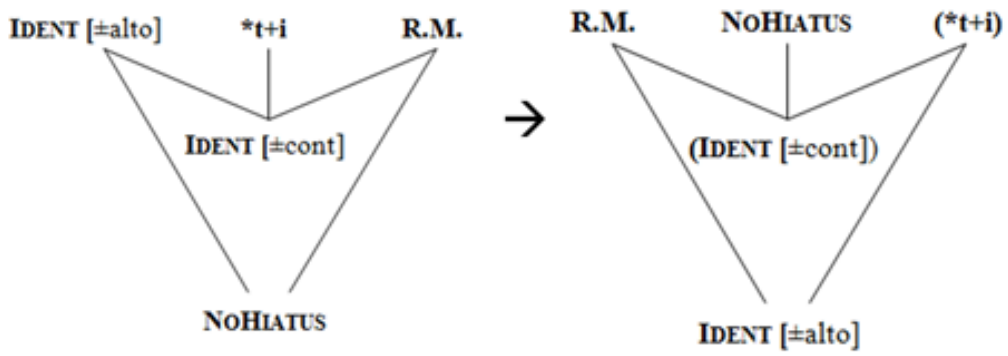

Como mostramos acima, a promoção de NoHiatus seria o responsável pela eliminação de formas como dórmio e sérvio, no português contemporâneo. Note-se que formas como durmo e sirvo satisfazem tanto NoHiatus quanto R.M. De forma análoga, a demoção de IDENT [ \pm alto] (abaixo de R.M.) permitiu que as médias da raiz pudessem ser alteadas para a satisfação de R.M., restrição que, segundo nossa análise, estaria alta desde o português arcaico.

\section{REFERÊNCIAS}

CANTIGAS DE SANTA MARIA. Disponível em: <http://csm.mml.ox.ac.uk/> Acesso em: 26 jun. 2016.

CANTIGAS MEDIEVAIS GALEGO-PORTUGUESAS. Disponível em: < http://cantigas.fcsh.unl. pt/>. Acesso em: 26 jun. 2016.

CLEMENTS, G. N. Place of articulation in consonants and vowels: a unified theory. Working Papers of the Cornell Phonetics Laboratory 5., 77-123, 1991.

COLAÇO, M. J.; CARDEIRA, E. Menço ou minto? Regularização de paradigmas verbais. Diacrítica, n. 27, v.1, p. 69-94, 2013.

FREITAS, H. F. R. Auto de partilha e testamento de Elvira Sanches. Revista da Academia Brasileira de Filologia, Rio de Janeiro, ano II, n. II, 2003. Disponível em: < http://www.filologia.org. br/abf/rabf/2/060.pdf>. Acesso em: 26 jun. 2016.

HARRIS, J. W. Evidence from Portuguese for the "Elsewhere Condition" in Phonology. Linguistic Inquiry, v. 5, n. 1, p 61-80, 1974.

HORA, D.; LUCENA, R. M. Conspiração e demoção: mecanismos de simplificação da estrutura silábica. Alfa, São Paulo, v. 52, n. 2, p. 351-369, 2008.

KAGER, R. Optamality Theory. Cambridge: CUP, 1999.

MATOS E SILVA, R. V. o português arcaico: fonologia, morfologia e sintaxe. 2. Ed. São Paulo: Contexto, 2013.

NEVINS, A.; RODRIGUES, C; TANG, K. The rise and fall of the L-shaped morpheme: diachronic and experimental studies. Probus: De Gruyter Mouton, 2015.

NUNES, J. J. Compêndio de gramática histórica portuguguesa (Fonética e Morfologia). Lisboa: Livraria Clássica Editora, 1969. 
PRINCE, A. Arguing Optimality. 2002. disponível em: < roa.rutgers.edu/article/view/572> Acesso em: 26 jun. 2016.

PRONPOR - Programa para a História da Língua Portuguesa. Disponível em: < http://www. prohpor.org/>. Acesso em: 26 jun. 2016.

RODRIGUES, M. C. O hiato no português: a tese da conspiração. Letras de Hoje, v. 42, n. 3, p. 7-26, 2007.

SCHWINDT, L. C. Paradigmatic correspondences in the brazilian portuguese verbal vowel System. Acta Linguistica Hungarica, v. 54, p. 393-40, 2007.

VAN OOSTENDORP, M. Expressing inflection tonally. Catalan Journal of Linguistics, v. 4, n. 1, p. 107-127, 2005.

WALKER, R. Weak triggers in vowel harmony. Natural Language and Linguistic Theory, v. 23, p. 917-989, 2005.

WETZELS, L. Mid-Vowel Alternations in the Brazilian Portuguese Verb. Phonology, v. 12, n. 2, p. 281-304, 1995.

WILliAMS, E. B. Do Latim ao Português. Tradução de Antônio Houaiss. Rio de Janeiro: Ed. Tempo Brasileiro, 1975.

Submetido em: 14/10/2015

Aceito em: 24/03/2016 